ACCEPTED MANUSCRIPT

\title{
Widely-tunable and sensitive optical sensor for multi-species detection in the mid-IR
}

To cite this article before publication: Awad Alquaity et al 2017 Meas. Sci. Technol. in press https://doi.org/10.1088/1361-6501/aa912b

\section{Manuscript version: Accepted Manuscript}

Accepted Manuscript is "the version of the article accepted for publication including all changes made as a result of the peer review process, and which may also include the addition to the article by IOP Publishing of a header, an article ID, a cover sheet and/or an 'Accepted

Manuscript' watermark, but excluding any other editing, typesetting or other changes made by IOP Publishing and/or its licensors"

This Accepted Manuscript is @ 2017 IOP Publishing Ltd.

During the embargo period (the 12 month period from the publication of the Version of Record of this article), the Accepted Manuscript is fully protected by copyright and cannot be reused or reposted elsewhere.

As the Version of Record of this article is going to be / has been published on a subscription basis, this Accepted Manuscript is available for reuse under a CC BY-NC-ND 3.0 licence after the 12 month embargo period.

After the embargo period, everyone is permitted to use copy and redistribute this article for non-commercial purposes only, provided that they adhere to all the terms of the licence https://creativecommons.org/licences/by-nc-nd/3.0

Although reasonable endeavours have been taken to obtain all necessary permissions from third parties to include their copyrighted content within this article, their full citation and copyright line may not be present in this Accepted Manuscript version. Before using any content from this article, please refer to the Version of Record on IOPscience once published for full citation and copyright details, as permissions will likely be required. All third party content is fully copyright protected, unless specifically stated otherwise in the figure caption in the Version of Record.

View the article online for updates and enhancements. 


\title{
Widely-tunable and sensitive optical sensor for multi-species detection in the mid-IR
}

\author{
Awad B.S. Alquaity, Bidoor Al-Saif and Aamir Farooq*
}

Clean Combustion Research Center, Physical Sciences and Engineering Division, King Abdullah University of Science and Technology (KAUST), Thuwal, 23955-6900, Saudi Arabia

*Corresponding author email: $\underline{\text { aamir.farooq@kaust.edu.sa }}$

\begin{abstract}
Pulsed cavity ringdown spectroscopy (CRDS) technique was used to develop a novel widely-tunable laserbased sensor for sensitive measurements of ethylene, propene, 1-butene and allene in the mid-IR. The use of an external-cavity quantum cascade laser (EC-QCL) enabled the sensor to cover a wide wavelength range from 10 to $11.1 \mu \mathrm{m}\left(900-1000 \mathrm{~cm}^{-1}\right)$ to detect multiple gases relevant to combustion and environment. The sensor operation was validated in a room-temperature static cell using well-characterized absorption lines of carbon dioxide near $938.69 \mathrm{~cm}^{-1}$ and $974.62 \mathrm{~cm}^{-1}$. Detection limits for ethylene, propene, 1-butene, and allene were measured to be 17, 134, 754 and 378 ppb, respéctively, at $296 \mathrm{~K}$ and 760 Torr for a single-pass pathlength of $70 \mathrm{~cm}$ with averaging time of $4 \mathrm{~ms}$. The excellent sensitivity of the optical sensor enabled it to measure the aforementioned gases at levels smaller than $1 \%$ of their recommended exposure limits. To the best of our knowledge, this is one of the first successful applications of the pulsed CRDS technique to measure trace levels of multiple gases in the $10-11 \mu \mathrm{m}$ wavelength region.
\end{abstract}

Keywords: Multi-species detection, cavity ringdown spectroscopy, air pollution monitoring, combustion diagnostics

\section{Introduction}

The monumental advancements in laser technology over the past few decades have made laser-based sensors ubiquitous in a wide array of applications including noninvasive medical diagnostics [1-3], environmental pollution monitoring [4,5], industrial process control [6,7], detection of explosives [8,9] and several others. Laser sensors have gained attention primarily due to their ability to carry out real-time, nonintrusive measurements of species with high sensitivity and selectivity. Recent improvements in laser technology such as the advent of external cavity quantum cascade lasers (EC-QCLs) with wide tuning 
ranges of the order of $100 \mathrm{~cm}^{-1}$ enable spectroscopic measurements of broadband absorbers as well as multiple species with a single laser. The ability of an EC-QCL based sensor to measure multiple species owing to its extensive tuning range is an enormous advantage when compared with competing diode laserbased sensors which can usually measure only a single species because of their narrow operating ranges. A widely-tunable laser when coupled with a mirror cavity that retains high reflectivity over a broad wavelength range enables trace detection of multiple species and has applications in environmental pollution monitoring, industrial gas sensing and combustion. In this vein, we have developed and validated a novel laser-based sensor that uses a widely tunable EC-QCL coupled to a moderately high finesse mirror cavity to obtain high sensitivity over a wide wavelength range from 10 to $11.11 \mu \mathrm{m}\left(1000-900 \mathrm{~cm}^{-1}\right)$. We demonstrate the high sensitivity of the sensor over a wide tuning range by measuring trace amounts of ethylene, propene, allene, and 1-butene, individually and in a multi-gas mixture.

Ethylene, propene, allene, and 1-butene play a crucial role in the oxidation and pyrolysis of large hydrocarbons, either as intermediates [10-12] or as precursors to a host of radical intermediates [13]. Ethylene and propene also play a significant role in the formation and growth of polycyclic aromatic hydrocarbons which are primary precursors of soot particles. Detection of trace amounts of volatile organic compounds such as ethylene and propene is vital in the study of air quality. Industrial emissions, waste incineration plants and vehicle exhaust fumes are the major sources of ethylene and propene in the atmosphere. Ethylene and propene can rapidly undergo oxidation reactions producing ground-level ozone $[14,15]$, which has adverse effects on crops and human health [16-19]. Moreover, the aforementioned target molecules are widely used as feedstock or intermediates in chemical and petroleum industries and thereby a single diagnostic that can measure all four gases in trace amounts will be invaluable in their leak detection.

Ethylene has previously been measured in trace concentrations using a variety of sensitive absorption techniques. Photoacoustic spectroscopy has been extensively used for monitoring trace ethylene in a number of studies. Altuzar et al. [20] developed a $\mathrm{CO}_{2}$ gas laser based photoacoustic spectrometer to measure ethylene concentrations in air samples from different locations in Mexico city. Weidmann et al. [5] developed an ethylene sensor based on direct absorption in a multi-pass Herriot cell to monitor ethylene from vehicle exhaust and in air samples from a busy urban tunnel. They reported a noise equivalent sensitivity of $30 \mathrm{ppb}$ for ethylene with 80 seconds of total acquisition time. Wahl et al. [21] developed an ultra-sensitive ethylene sensor based on cw-cavity ringdown spectroscopy technique to measure trace ethylene levels in a fruit packing facility. They reported detection limit of $2 \mathrm{ppb}$ with 4.4 minutes of measurement time. Manne et al. [22,23] performed a proof-of-concept study to measure ethylene using four 
strategies, namely pulsed cavity ringdown spectroscopy, cavity-enhanced spectroscopy [22], intrapulse and interpulse spectroscopic techniques with a multi-pass cell [23]. They reported detection limits in the range of $5 \mathrm{ppb}$ to $130 \mathrm{ppb}$ with 5 to 10 seconds of integration time.

Recently, Chrystie et al. [15] developed a laser-based sensor to non-intrusively measure propene concentrations in a chemical reactor (shock tube). In general, there has been little work on the' development of laser-based sensors for the detection of propene, allene or 1-butene. Detection of propene, allene, and 1butene has traditionally been carried out using mass spectrometry [12] or gas chromatography techniques $[13,24]$; both of which require sampling using physical probes. The narrow tuning range of previously used laser sources generally limited the optical sensors to the detection of a single molecule and this probably made laser sensors unappealing as compared to the gas sampling techniques. The wide tuning range and high sensitivity of the current sensor, coupled with the traditional advantages of laser-based sensors such as non-intrusiveness, portability, robustness and rapid response, make it better suited for environmental monitoring and industrial gas sensing applications.

In this work, we have implemented pulsed cavity ringdown spectroscopy (pulsed CRDS) with ringdown mirrors of $99.5 \%$ reflectivity. The wide tuning range of the EC-QCL coupled with the relatively flat reflectivity curve of the ringdown mirrors used here allowed us to develop a sensor with a broad wavelength operating range. In what follows, we present a detailed description of the design of our sensor. We then describe the validation of the sensor using $\mathrm{CO}_{2}$ gas and describe sensor optimization. We then demonstrate the sensor to measure small amounts of ethylene, propene, allene and 1-butene. Finally, we show the capability of the sensor to measure trace amounts of gases in a multi-gas mixture. To our knowledge, this is the first implementation of pulsed CRDS with EC-QCL to achieve a highly sensitive and widely tunable sensor in the mid-IR (900-1000 $\left.\mathrm{cm}^{-1}\right)$. Additionally, this work represents the first laser-based measurements of trace amounts of propene, allene, and 1-butene.

\section{Theory of cavity ringdown spectroscopy}

Cavity ringdown spectroscopy (CRDS) was introduced almost three decades back, in 1988, by O'Keefe and Deacon [25] and since then has been extensively used for sensitive detection of gas phase [26-30] and liquid phase samples [31,32]. Cavity ringdown may be implemented with pulsed or continuous-wave lasers to develop highly sensitive gas sensors. A brief description of CRDS implemented with pulsed lasers is given here. In pulsed CRDS, the light pulse from a laser is admitted into a stable optical cavity configuration and undergoes númerous passes. When the laser pulse ends, the light inside the cavity undergoes an exponential 
decay. The exponential decay rate is dependent on the reflectivity of mirrors forming the cavity, the length of the cavity, and absorption losses inside the cavity. The time constant of the exponential decay or the ringdown time is the time taken for the light intensity to fall to 1/e of its initial value. It is given as:

$$
\tau=L /(c[(1-R)+\alpha L])
$$

In the absence of any absorbing molecules inside the cavity, the ringdown time is given as:

$$
\tau_{0}=L /(c[(1-R)])
$$

In the above equations, $L$ is the total length of the cavity, $c$ is the speed of light, $R$ is the reflectivity of the mirrors forming the cavity and $\alpha$ is the absorption coefficient in $\mathrm{cm}^{-1}$. The absorption coefficient can be calculated from Eq. (1) and Eq. (2) as:

$$
\alpha=\frac{1}{c}\left(\frac{1}{\tau}-\frac{1}{\tau_{0}}\right)
$$

The absorption coefficient, $\alpha$, is a function of the total pressure of the gas, $P$, the mole fraction of the absorbing species, $X$, the linestrength, $S$, and the lineshape $\phi_{\nu}$ :

$$
\alpha=S(T) P X \phi_{v}(P, T)
$$

Equation (4) enables the determination of the mole fraction of the absorbing species when spectroscopic parameters $\left(S\right.$ and $\left.\phi_{\nu}\right)$ are known.

\section{Experimental apparatus}

The experimental setup for the designed sensor is shown in Fig.1. We used a pulsed EC-QCL (Daylight Solutions 11100-UT), tunable over 9.53-12.95 $\mu \mathrm{m}\left(775-1020 \mathrm{~cm}^{-1}\right)$, with a maximum average power of 15 $\mathrm{mW}$. Laser pulse widths can be varied between 40 to $500 \mathrm{~ns}$ and repetition frequencies as high as $100 \mathrm{kHz}$ are possible. Single mode emission at the wavelength of interest was achieved by adjusting the laser head temperature and diffraction grating orientation via the laser controller. Single mode emission was ensured by sending the laser beam to a spectrum analyzer (Bristol 721). The IR beam emitted by EC-QCL was coaligned with a $10 \mathrm{~mW}$ He-Ne laser $(632 \mathrm{~nm})$ to facilitate the cavity alignment process. The IR beam (beam diameter $\approx 2 \mathrm{~mm}$ ) emerging from the EC-QCL head was directed into an optical cavity formed by two plano-concave mirrors (II-VI Infrared) with $1 \mathrm{~m}$ radius of curvature, 1" diameter, and a manufacturer specified reflectivity of $99.5 \%$ at $10.6 \mu \mathrm{m}\left(943.39 \mathrm{~cm}^{-1}\right)$. The ringdown mirrors were placed $70 \mathrm{~cm}$ apart to 
form a stable optical cavity configuration. A plano-convex lens (ZnSe, $500 \mathrm{~mm}$ focal length) was positioned between the EC-QCL head and the ringdown cavity to improve the mode-matching between the laser beam and the TEM 00 mode of the cavity. A concave mirror (Aluminum, $100 \mathrm{~mm}$ focal length) stationed at the exit of the optical cavity was used to focus the IR beam on a thermoelectrically-cooled photovoltaic detector (Vigo PVMI 3TE-10.6) with a bandwidth of $10 \mathrm{MHz}$. The detector signal was recorded with a digital oscilloscope (Tektronix DPO 3014) having a sampling rate of $2.5 \mathrm{GS} / \mathrm{s}$.

Although the EC-QCL can emit IR radiation over a wide wavelength range (9.53-12.95 $\mu \mathrm{m})$, its tuning range is not mode-hop free. Therefore, laser head temperature and grating orientation had to be iteratively tuned to avoid mode-hops. However, the strategy to tune temperature and diffraction grating was not successful for all desired wavelengths. Despite this limitation, the wide tunability of the EC-QCL proved to be an enormous advantage in our quest to develop a sensor capable of detecting multiple species in trace amounts. The output wavelength of the EC-QCL was quite reproducible from one day to next and the drift in the emitted wavelength was negligible over long periods (> 8 hours) of continuous operation.

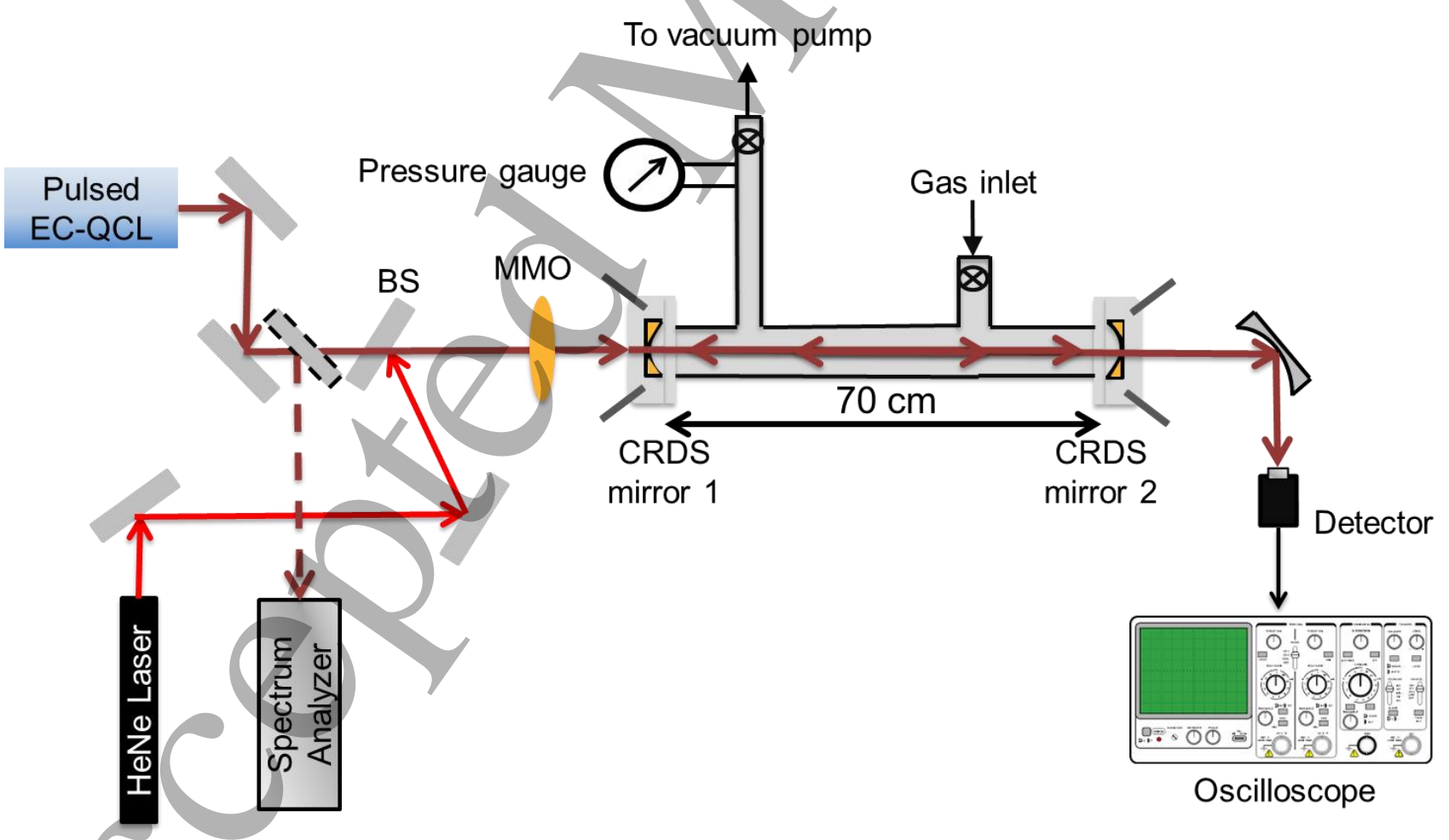

Figure 1. Experimental setup used for pulsed CRDS measurements in the static cell. BS: Beam Splitter, MMO: Mode matching optic. 
To make the best use of the energy available from the pulsed laser, the laser pulse width was varied to identify its optimum value. The frequency chirp of the laser or the laser linewidth increases from $0.032 \mathrm{~cm}^{-}$ ${ }^{1}$ at $80 \mathrm{~ns}$ pulse width to $0.08 \mathrm{~cm}^{-1}$ at $120 \mathrm{~ns}$ pulse width, as measured in an earlier study [30]. It is desirable to minimize frequency chirp as it can lead to artificial broadening of narrow spectral lines. However, high detector signal is also a necessity. Therefore, to minimize frequency chirp while ensuring high SNR of the detector signal, laser pulse width of $100 \mathrm{~ns}$ having a frequency chirp of $0.064 \mathrm{~cm}^{-1}$ was used throughout this work.

The gas cell, with the two ringdown mirrors at its two ends, was connected to a gas tank, a vacuum pump, and two calibrated pressure transducers (MKS 627D capacitance manometers with 1000 and 10000 Torr full-scale pressure range and accuracy of $0.12 \%$ ). High purity propene (99.95\%), allene (99.5\%), 1-butene (99.95\%) gases, dilute mixture of ethylene (1051 ppm ethylene in argon), dilute mixture of carbon dioxide (1.05\% carbon dioxide in nitrogen), ultra-pure nitrogen (99.999\%), and Ultra-pure argon (99.999\%) were used for the experiments. The diluted mixtures of individual gases were prepared manometrically using a gas handling system. The pressure in the gas handling system was monitored by two pressure transducers (MKS 627D capacitance manometers with 100 and 1000 Torr full scale range). In the majority of cases, multiple dilution steps were required to achieve the desired concentration of target gases.

\section{Sensor validation and optimization}

The sensor was validated using carbon dioxide as a test molecule because its spectroscopic parameters (linestrength, lineshape) are very well-known [33]. Carbon dioxide has relatively strong absorption lines in the $930-985 \mathrm{~cm}^{-1}$ wavelength region and the ringdown mirrors have their maximum reflectivity near 944 $\mathrm{cm}^{-1}$. However, ethylene has a very strong vibrational band $\left(v_{7}\right)$ centered near $949.533 \mathrm{~cm}^{-1}$ and even trace amount of ethylene, present as an impurity, can cause appreciable interference. Therefore, simulations were performed using the HITRAN database [33] to identify absorption lines of $\mathrm{CO}_{2}$ where the interference from ethylene is minimal. Subsequently, two absorption lines of $\mathrm{CO}_{2}$ centered near $938.69 \mathrm{~cm}^{-1}\left(\left(\begin{array}{llll}1 & 0 & 0 & 01\end{array}\right) \rightarrow\left(\begin{array}{ll}0 \\ 0\end{array}\right.\right.$

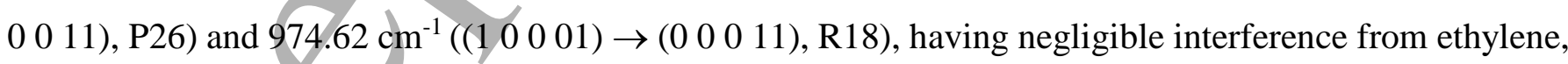
were selected to demonstrate the wide tuning range of this sensor.

With a view to minimizing the effect of artificial broadening due to the frequency chirp of the laser, absorption measurements of $\mathrm{CO}_{2}$ were performed at a relatively high pressure of 1200 Torr. Figure 2 shows a comparison between the simulated and measured absorption coefficients for the absorption lines centered near $938.69 \mathrm{~cm}^{-1}$ and $974.62 \mathrm{~cm}^{-1}$. Each measured data point was obtained by using Eq. (3) after determining 
the ringdown time for pure $\mathrm{N}_{2}\left(\tau_{0}\right)$ and for a $1.05 \% \mathrm{CO}_{2} / \mathrm{N}_{2}$ mixture $(\tau)$. The measured absorption coefficients (red square) agree very well with the simulated absorption coefficients (black line) in both wavelength regions, thereby validating the pulsed-CRDS setup.

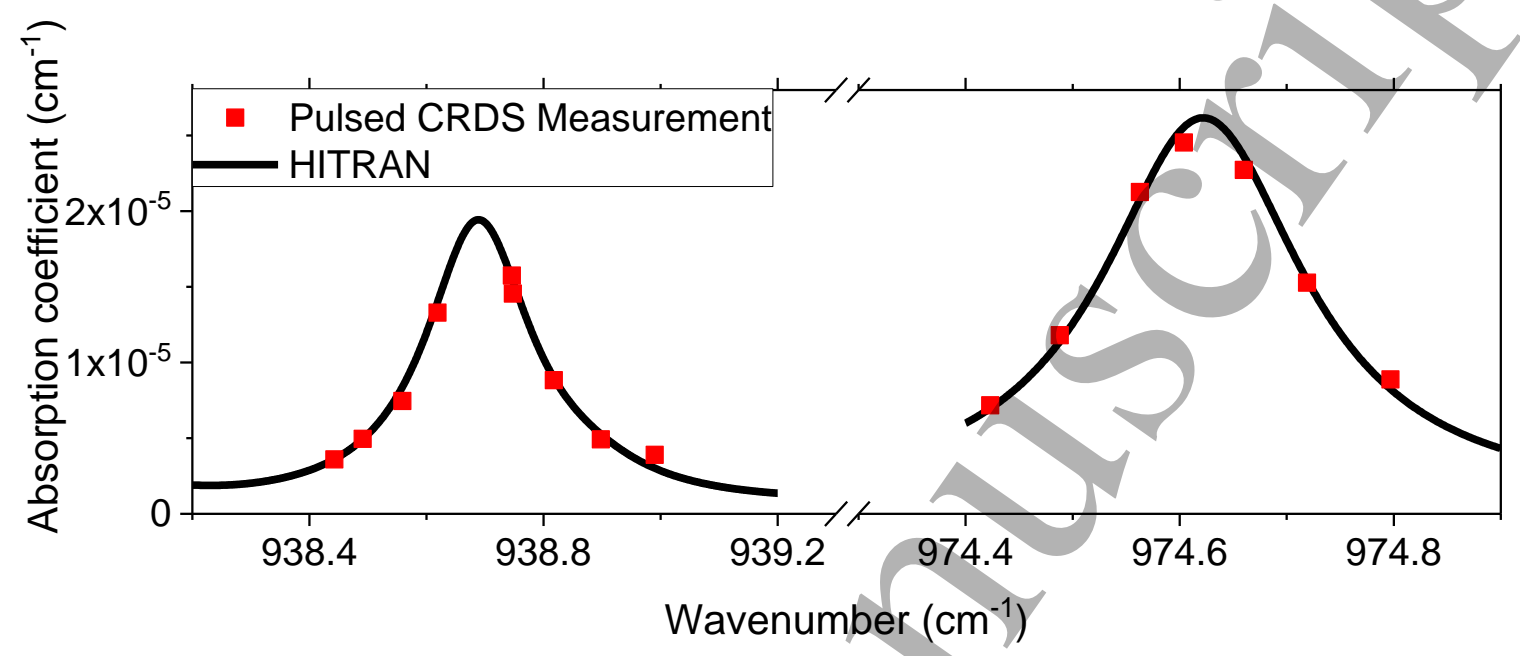

Figure 2. Comparison of measured absorption coefficients (red squares) with HITRAN simulations [33]. Mixture: $1.05 \% \mathrm{CO}_{2} / \mathrm{N}_{2} ; \mathrm{T}=296 \mathrm{~K} ; \mathrm{P}=1200$ Torr.

Ringdown times were measured in an optical cell filled with ultra-pure Argon (760 Torr pressure) across the entire wavelength range of the sensor $\left(900-1000 \mathrm{~cm}^{-1}\right)$ in steps of $\sim 10 \mathrm{~cm}^{-1}$. Figure 3 shows the measured ringdown time and the calculated mirror reflectivity as a function of wavenumber. The mirror reflectivity at $950 \mathrm{~cm}^{-1}$ was found to be $99.45 \%$ which compares well with the manufacturer quoted value of $99.5 \%$. The ringdown time and mirror reflectivity are largest at the center $\left(950 \mathrm{~cm}^{-1}\right)$ of the mirror curve and drop off on either side. However, the variation is not too significant and the sensor can be used to make species measurements over the entire target wavelength range of $900-1000 \mathrm{~cm}^{-1}$. 


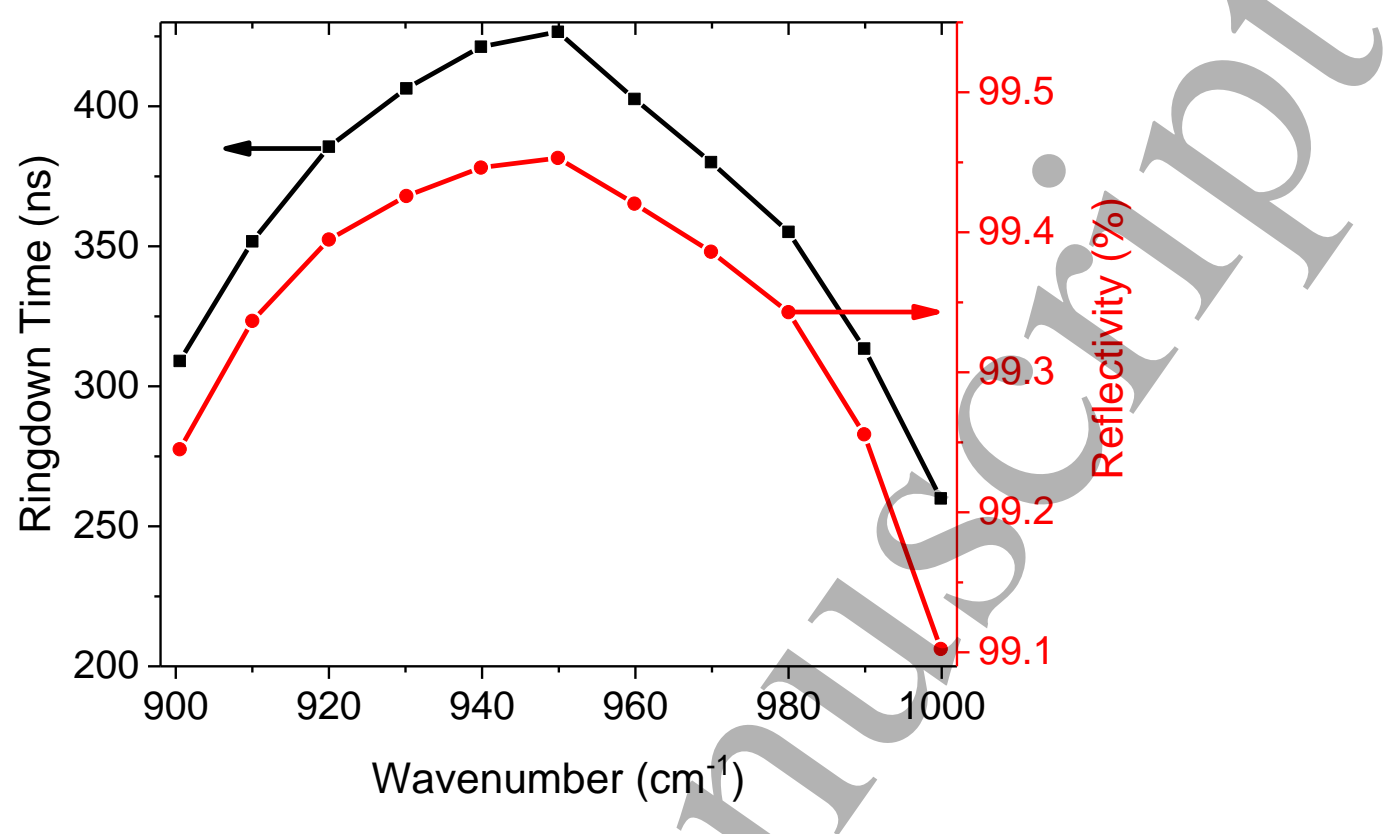

Figure 3. Ringdown time and mirror reflectivity as a function of wavenumber

With a view to determine the minimum detection limit and optimum averaging time, Allan Variance was calculated at each wavelength of interest. The Allan Variance was computed using the decay rate (inverse of ringdown time) and was scaled by the speed of light to make it equivalent to absorption coefficient [34]. The static cell was filled with ultra-pure argon to a pressure of 760 Torr, and the detector signal was recorded at each wavenumber step for 4000 ring-down events which corresponds to a time period of $40 \mathrm{~ms}$ (laser repetition rate is $100 \mathrm{kHz}$ ). In the current work, Allan Variance was calculated using the new algorithm proposed by Huang and Lehmann [34] as it leads to significant reduction in noise and more accurate determination of the optimum averaging time when compared with the traditional algorithm. The Allan Variance drops very steeply initially and reaches minima near an averaging time of $\sim 4$ ms (corresponding to 400 ringdown events) for almost all the wavenumbers, as shown in Fig.4. Huang and Lehmann[34] had obtained a similar optimal ayeraging size of 500 ringdown events in their work; however, their corresponding optimal averaging time was $72 \mathrm{~s}$ because of the significantly larger time-gap between successive ringdown events. The high repetition rate of the laser $(100 \mathrm{kHz})$ used in our work enables us to achieve millisecond time resolution even after averaging 400 events and this feature is valuable for carrying out real-time measurements of species in transient environments. For each ringdown measurement reported here, the extracted ringdown times were averaged over 400 ringdown events. For the averaging time of 4 $\mathrm{ms}$, the Allan Variance is less than $1.9 \times 10^{-7} \mathrm{~cm}^{-1}$ across the entire wavelength range of the sensor. It is to be noted that the averaging time of $4 \mathrm{~ms}$ is required to measure the absorbance at a specific wavelength and 
is not the time resolution of the diagnostic to measure the concentration of a given species. Measuring the concentration of a given species in a mixture necessitates the measurement of $\tau$ and $\tau_{0}$ at one or more wavelengths, thereby increasing the time required to determine the concentration of a species. In the current diagnostic, since the laser has to be tuned manually from one wavelength to the next, it is not possible to assign a time resolution. However, for the case of the concentration being extracted from absorbance measurement at a single wavelength, the concentration measurements will have a time resolution of $4 \mathrm{~ms}$.

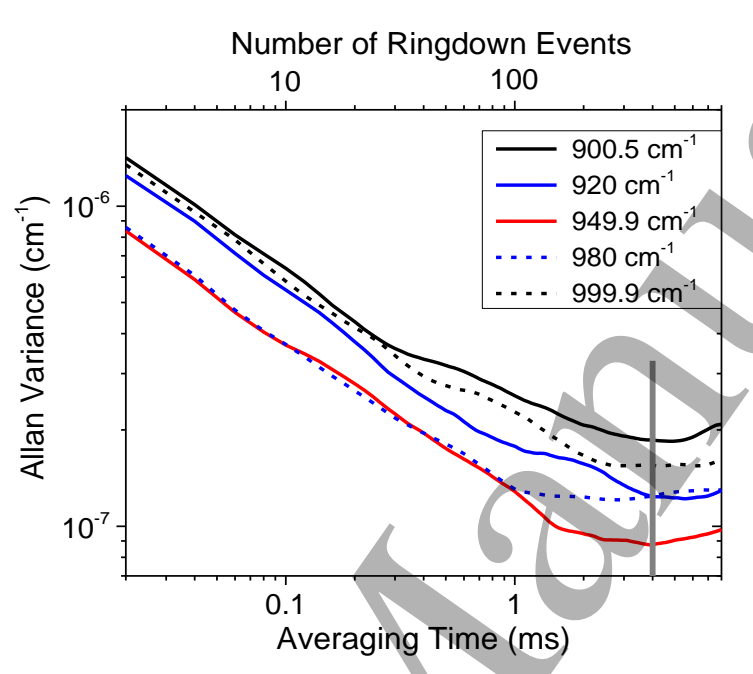

Figure 4. Allan Variance as a function of averaging time for different wavenumbers. The gray vertical line indicates the location of minimum Allan variance.

The high sensitivity of the sensor over a wide tuning range of $100 \mathrm{~cm}^{-1}$ makes it an ideal diagnostic to measure trace concentrations of multiple gases. To demonstrate the capability of the sensor for multi-species detection, four hydrocarbon molecules (ethylene, propene, allene and 1-butene) with strong absorption bands in the operating range of the sensor were selected (Fig.5). Due to the frequency chirp of the laser, estimated to be $0.064 \mathrm{~cm}^{-1}$ for a pulse width of $100 \mathrm{~ns}$, the sensor is best suited to detect molecules with broad spectral features as selected here. Figure 6 shows simulated absorption coefficients for trace amounts of the four molecules at a nominal temperature of $296 \mathrm{~K}$ and pressure of 760 Torr. The simulated absorption coefficients shown here were obtained by scaling the absorbance measurement reported by Pacific Northwest National Laboratory (PNNL) database [35] assuming a path length of $1 \mathrm{~cm}$. At the given experimental conditions, the peak absorption coefficients for the ppm-level concentration of all gases are larger than $3.7 \times 10^{-5} \mathrm{~cm}^{-1}$ which is about two orders of magnitude higher than the sensor detection limit of $1.9 \times 10^{-7} \mathrm{~cm}^{-1}$, thereby enabling the sensor to measure trace amounts of these hydrocarbon gases. The absorption peaks for all molecules are very well separated except the peaks of propene and 1-butene which lie within $0.9 \mathrm{~cm}^{-1}$ of each other. Ethylene has strong absorption band $\left(v_{7}\right)$ centered near $949.41 \mathrm{~cm}^{-1}$ that 
can be attributed to the $\mathrm{CH}_{2}$ wagging, while propene has strong absorption band ( $\left.v_{19}\right)$ centered near 912.62 $\mathrm{cm}^{-1}$ due to the $\mathrm{CH}_{2}$ twisting and wagging [36]. Strong peaks of 1-Butene are observed near $911.71, \mathrm{~cm}^{-1}$ which are attributed to the $\mathrm{CH}_{2}$ out-of-plane bending mode [37]. Allene absorption near $901.8 \mathrm{~cm}^{-1}$ is assigned to one of the weaker lines of the $v_{4}$ vibrational band centered at $865 \mathrm{~cm}^{-1}$ which is attributed to the $\mathrm{CH}_{2}$ twisting [38]. Absorption measurements for all four species were carried out near the peaks of their absorption coefficients.

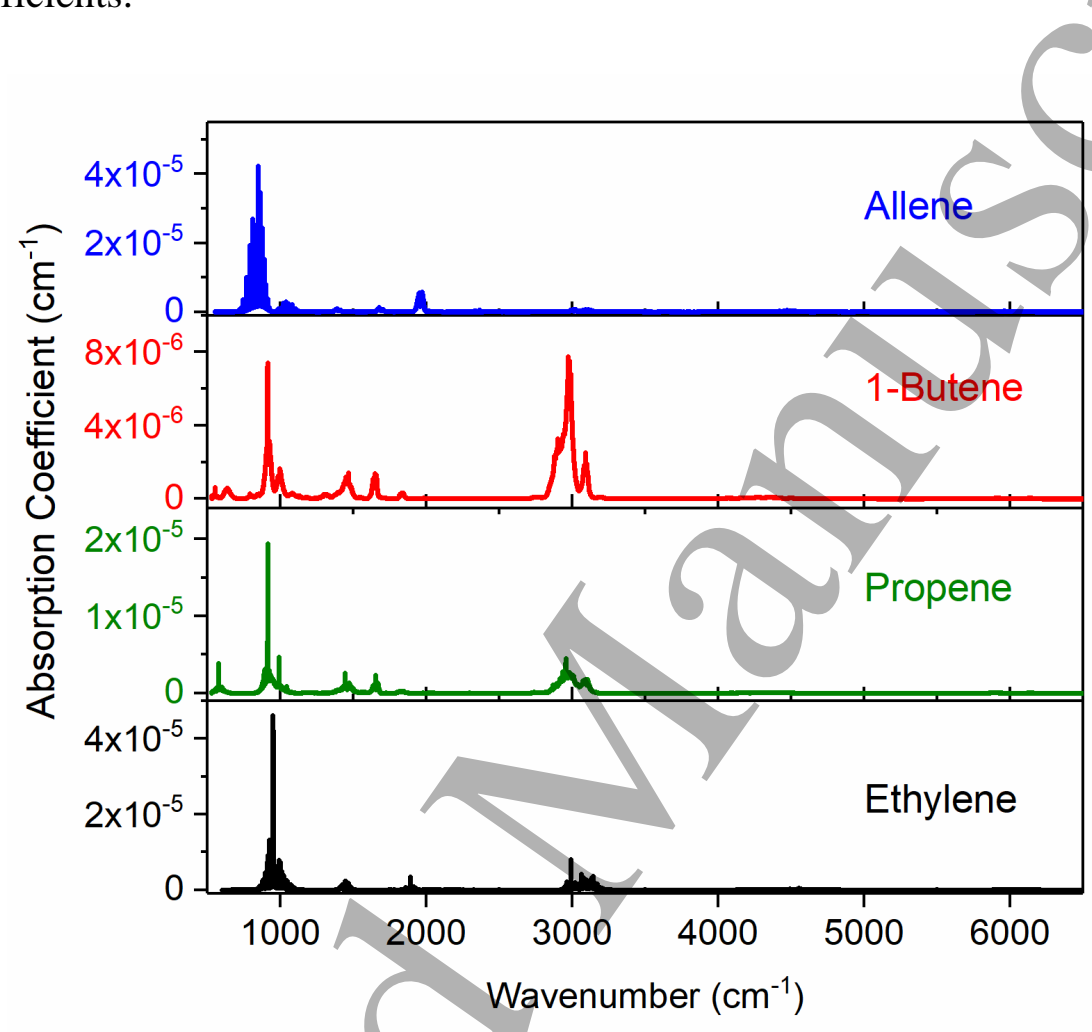

Figure 5. Simulated absorption coefficients of selected target gases. Mole fraction $=1 \mathrm{ppm}$; $\mathrm{T}=296 \mathrm{~K} ; \mathrm{P}=760$ Torr. 


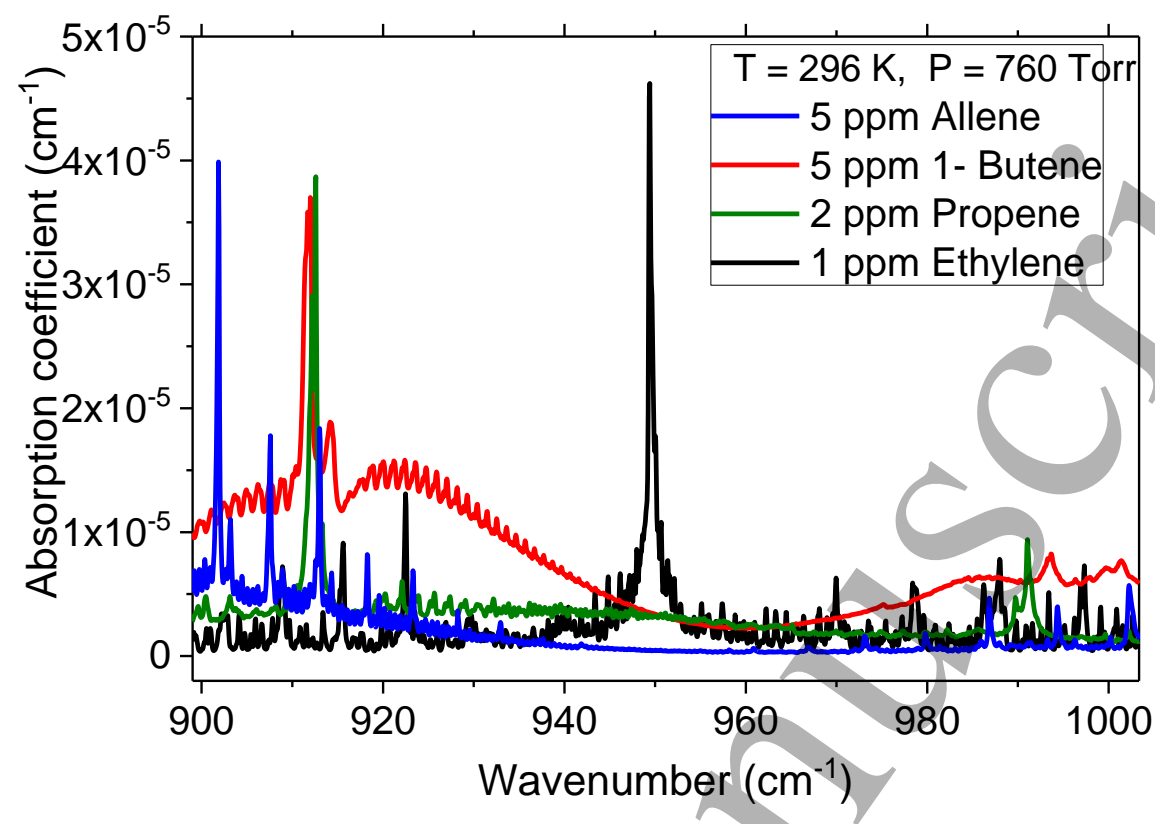

Figure 6. Simulated absorption coefficients of selected target gases over the operating wavelength range of the sensor.

\section{Results and discussion}

\subsection{Trace Gas Mixtures}

The capability of the sensor to measure trace concentrations was initially demonstrated by measuring small amounts of ethylene, propene, allene and 1-butene individually. Measured absorption coefficients were compared with the PNNL database [35] as it is the most reliable source for the absorption cross-sections of these molecules. All measurements reported here were performed at a nominal temperature of $296 \mathrm{~K}$ and pressure of 760 Torr; measured data are shown in Fig. 7. As discussed earlier, the mode-hop of the laser does not permit absorption coefficient measurements at constant wavelength intervals. The measured absorption coefficients for all four hydrocarbons agree very well with the PNNL database which confirms the sensor accuracy and sensitivity to trace amounts of target species. 


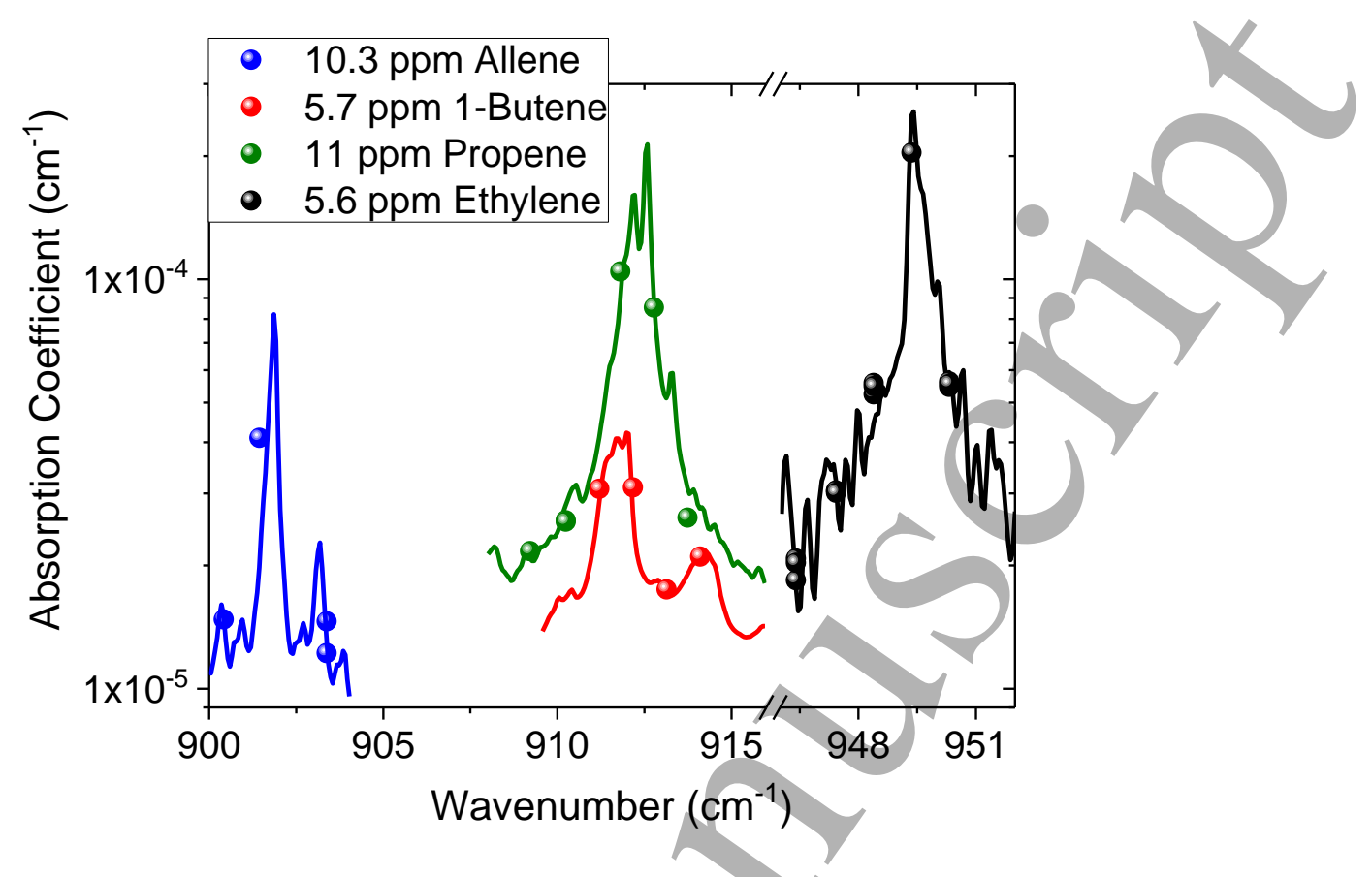

Figure 7. Comparison of measured absorption coefficients (symbols) with the PNNL Database (lines) [35]. T = $296 \mathrm{~K}$; $P=760$ Torr.

Representative raw detector signals for the ringdown events of all four target molecules and singleexponential fits to the experimental data are shown in Fig. 8 . The single-exponential function fits very well to the measured detector signals for all gases used in this study and over a range of concentrations. The rindown event for the $5.6 \mathrm{ppm}$ ethylene/argon mixture represents the largest absorption coefficient measured in this study, and the high quality of single-exponential fit for the small ringdown time of $113 \mathrm{~ns}$ demonstrates that the frequency chirp of the laser does not cause multi-exponential decays or other nonidealities at the experimental conditions used in this study (296 K and 760 Torr). 

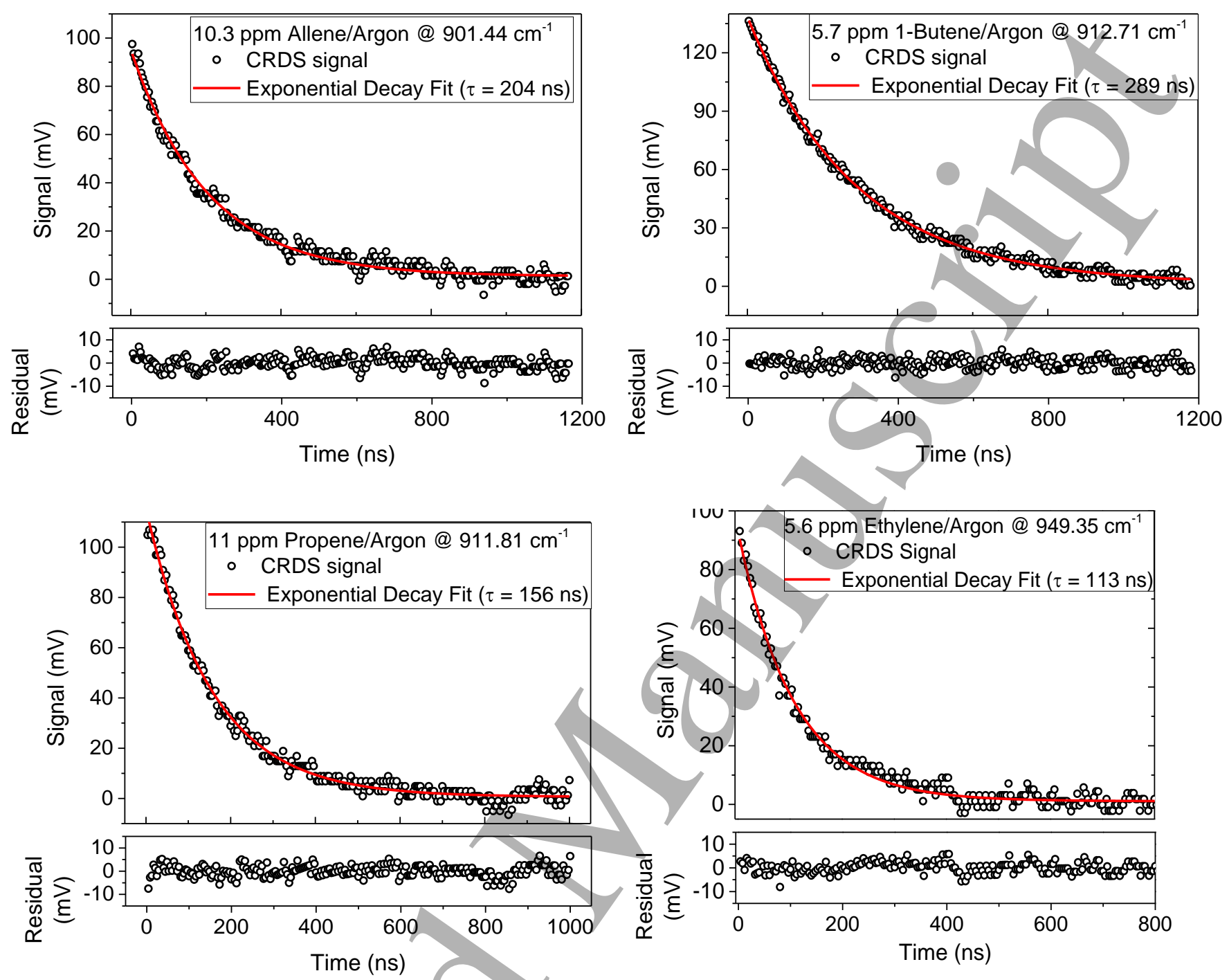

Figure 8. Representative detector signals during ringdown events, single-exponential decay fit to data and residuals for the four target gases.

\subsection{Detection Limits}

Detection limits for individual gases were obtained by successively diluting gas mixtures in argon bath gas and measuring the absorption coefficient at each dilution step till the measured absorption coefficient reached an asymptotic value, as shown in Fig.9 for propene. Similar trends were obtained for the other 3 molecules and the results are listed in Table 1. The detection limits for all gases follow the same trend as observed in Allan Variance analysis (Fig.4) with allene measured near $902.4 \mathrm{~cm}^{-1}$ having the largest value of the detection limit, and ethylene measured near $950.08 \mathrm{~cm}^{-1}$ having the lowest detection limit. However, the detection limits calculated using Allan Variance analysis are an order of magnitude smaller than the values obtained using mixture dilution method. Mixture dilution method leads to larger values for detection 
limits because it is affected by uncertainties in the ringdown times for both the absorber gas and the bath gas (argon), whereas the Allan Variance analysis only considers the uncertainties in the ringdown times of the bath gas. Therefore, the mixture dilution method provides more realistic values of the detection limits and has been subsequently used to report the minimum detection limit for each molecule at a nominal temperature of $296 \mathrm{~K}$ and pressure of 760 Torr (Table 1). The detection limits in terms of ppb were calculated at the peak absorption coefficient for each molecule within the operating wavelength range of the sensor and were scaled from the PNNL database for each molecule. The detection limits presented here provide a very good estimate of the uncertainty in the absorption measurements reported in this study.

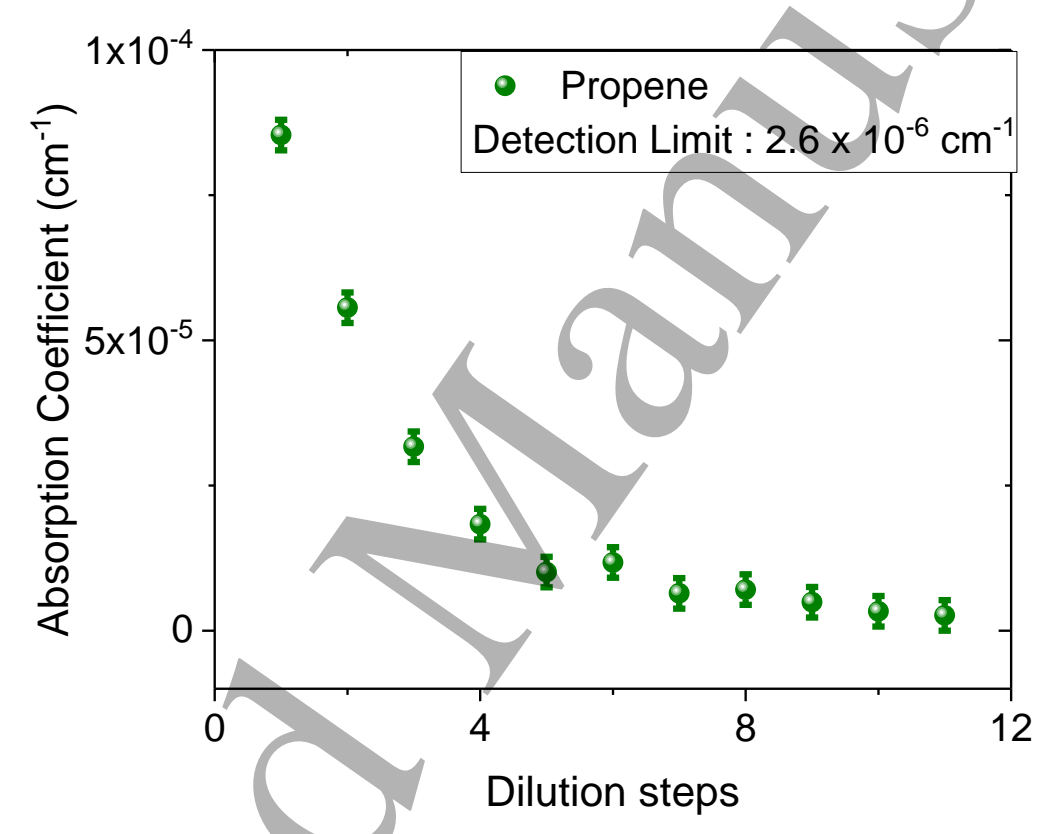

Figure 9. Absorption coefficient as a function of mixture (propene / Ar) dilution. $T=296 \mathrm{~K} ; \mathrm{P}=760$ Torr.

Table 1. Detection limits determined using the mixture dilution method.

\begin{tabular}{|c|c|c|c|}
\hline Molecule & Wavenumber $\left[\mathbf{c m}^{-1}\right]$ & Detection Limit $\left[\mathbf{c m}^{-1}\right]$ & Detection Limit [ppb] \\
\hline Allene & 902.4 & $6 \times 10^{-6}$ & 754 \\
\hline 1-Butene & 912.71 & $2.8 \times 10^{-6}$ & 378 \\
\hline Propene & 912.11 & $2.6 \times 10^{-6}$ & 134 \\
\hline Ethylene & 950.08 & $7.6 \times 10^{-7}$ & 17 \\
\hline
\end{tabular}


Here, we discuss the detection limit of our sensor with other competing methods. Assuming an optimistic value of detection limit of $1 \%$ absorbance using direct absorption spectroscopy [39], the minimum detection limit for $70 \mathrm{~cm}$ static cell will be $1.43 \times 10^{-5} \mathrm{~cm}^{-1}$, which translates to 2.38 to 18.8 times lower sensitivity compared to the pulsed CRDS sensor described in the current study. Since the pulsed CRDS sensor covers the wavenumber region containing highly strong absorption bands for all molecules of interest (Fig.5), the current sensor will be more sensitive compared to laser sensors in other wavelength regions, such as in the near-IR as long as mirrors with similar reflectivity are utilized. It is pertinent to point out that higher reflectivity mirrors are easily available in the near-IR region, which when coupled with a cw laser to develop cw-cavity ringdown spectroscopy based sensor maylachieve higher detection limits [21]. However, the spectral features of hydrocarbons are not as well separated in the near-IR region and interference from $\mathrm{CO}_{2} / \mathrm{H}_{2} \mathrm{O}$ tend to more problematic.

Fourier Transform Infrared (FTIR) spectrometer studies have typically been carried out to measure absorption cross-section of various absorption bands and use integrated absorbance [36-38,40], though single-point absorbance measurements as used in the current study are also possible. FTIR spectrometers have few advantages over laserbased sensors notably their ability to cover wide wavelength ranges, typically from near IR to mid IR. However, FTIR measurements typically require a lot of averaging which limits their time resolution, and FTIR spectrometers tend to be bulky thereby making these unfeasible for field measurements as compared to the compact laser-based sensors. Although the QCL system used in the current work had some mode-hop issues, improvements in QCL technology are happening at a rapid pace and the new systems are expected to sweep through large wavelength regions rapidly without mode-hops.

\subsection{Multi-gas Mixtures}

The ability of the sensor to detect multiple species simultaneously was demonstrated by applying the sensor to a multi-gas mixture containing trace amounts of the target gases. The multi-gas mixture composition was selected to contain gases at $1 \%$ of their 8 -hour time-weighted-average (TWA) exposure limits. The TWA exposure limits for ethylene, propene, and allene are $200 \mathrm{ppm}$ [41], $500 \mathrm{ppm}$ [41], and $1000 \mathrm{ppm} \mathrm{[42],}$ respectively. Therefore, a mixture containing $2.2 \mathrm{ppm}$ ethylene, $5.2 \mathrm{ppm}$ propene, and $10 \mathrm{ppm}$ allene was prepared manometrically in argon bath gas. Multiple dilution steps were used to prepare such a mixture. Figure 10 shows the comparison of measured absorption coefficients with those calculated using the PNNL database. The total calculated (PNNL) absorption coefficient of the mixture is shown in gray triangles, while the measured total absorption coefficient is marked with red hollow circles. The total absorption coefficient was measured at 4 specific wavenumbers - three near the peaks of the three species and one near an offline ethylene frequency. The concentration of ethylene may be calculated using differential absorption strategy since the contribution of allene and propene to the total absorbance at the on-peak and off-peak frequencies of ethylene are almost identical and can thus be subtracted. Using this methodology, the 
ethylene concentration was calculated to be $2.3 \mathrm{ppm}$, which is very close to the manometric value of 2.2 ppm. The total absorption coefficient measured at the two other wavenumbers $\left(901.55 \mathrm{~cm}^{-1}\right.$ and 911.983 $\mathrm{cm}^{-1}$ ) may be written as:

$$
\alpha_{\mathrm{e}} \mathrm{X}_{\mathrm{e}}+\alpha_{\mathrm{p}} \mathrm{X}_{\mathrm{p}}+\alpha_{\mathrm{a}} \mathrm{X}_{\mathrm{a}}=\text { Total absorption coefficient }
$$

where $\alpha$ is the absorption coefficient and $\mathrm{x}$ is the mole fraction. The subscripts $\mathrm{e}, \mathrm{p}$, and a represent ethylene, propene, and allene, respectively. Writing Equation (5) for both wavenumbers $\left(901.55 \mathrm{~cm}^{-1}\right.$ and 911.983 $\mathrm{cm}^{-1}$ ), and substituting in the absorption coefficients for all gases and mole fraction of ethylene, results in a system of two linear equations containing two unknowns, the mole fraction of propene $\left(\mathrm{x}_{\mathrm{p}}\right)$ and the mole fraction of allene $\left(\mathrm{x}_{\mathrm{a}}\right)$. The equations are shown below for $901.55 \mathrm{~cm}^{-1}$ and $911.983 \mathrm{~cm}^{-1}$, respectively:

$$
\begin{gathered}
1.45 x_{p}+2.8 x_{a}=38.12 \\
10.4 x_{p}+1.16 x_{a}=65.52
\end{gathered}
$$

On solving the above set of linear equations, we obtain $\mathrm{x}_{\mathrm{p}}$ to be $5.1 \mathrm{ppm}$ and $\mathrm{x}_{\mathrm{a}}$ to be $11 \mathrm{ppm}$. The mole fraction of propene is within $2 \%$ of the expected value of $5.2 \mathrm{ppm}$, whereas the mole fraction of allene is $10 \%$ higher than the expected value of $10 \mathrm{ppm}$. The overestimation of allene is possibly due to the contribution of impurities (other hydrocarbons such as butene in the allene/argon mixture) to the total measured absorbance near $901.55 \mathrm{~cm}^{-1}$. Mode-hopping of the EC-QCL near the allene peak did not permit measurements near the allene peak $\left(901.85 \mathrm{~cm}^{-1}\right)$. These measurements demonstrate the capability of the sensor to accurately measure trace amounts of hydrocarbon gases in a multi-gas mixture, which makes this sensor an attractive candidate for environmental pollution monitoring and gas sensing in petrochemical industries. 


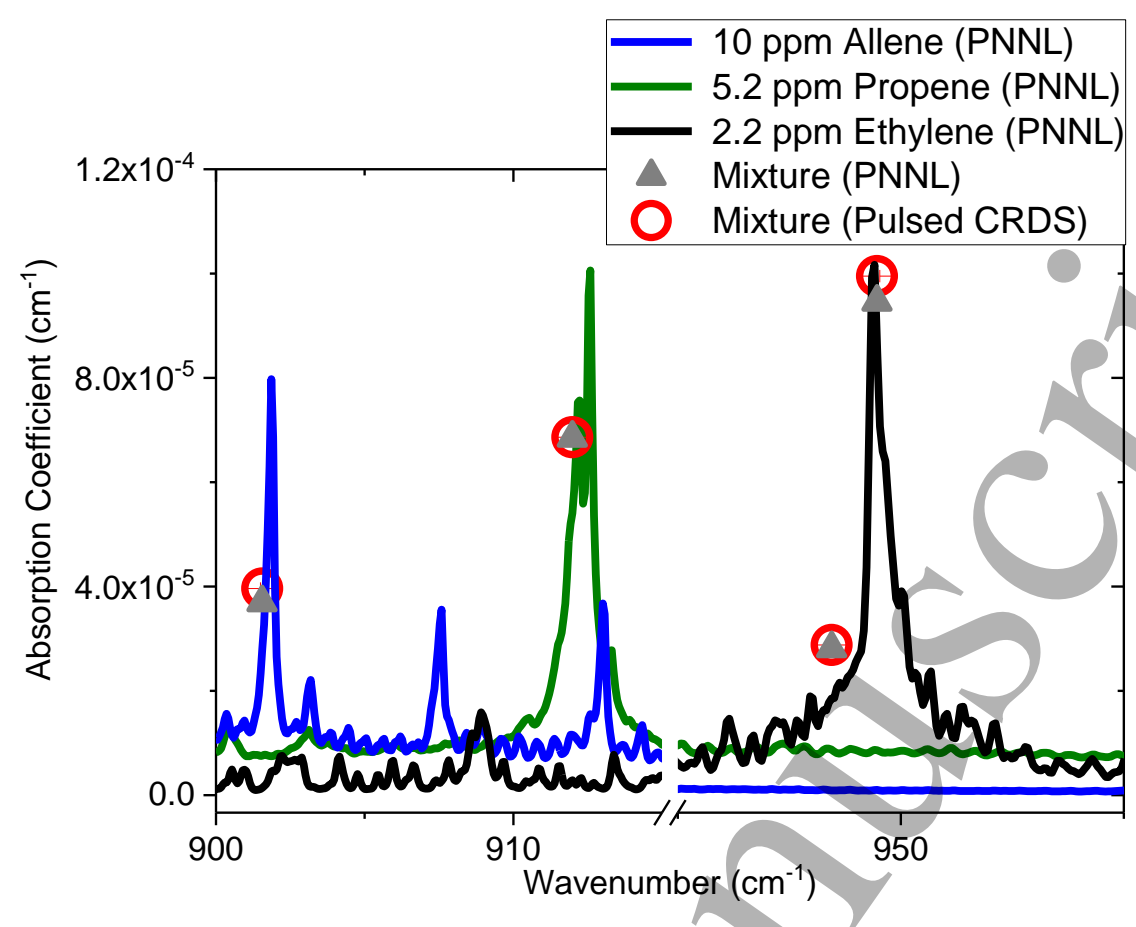

Figure 10. Absorption coefficients for multi-gas mixture containing $2.2 \mathrm{ppm}, 5.2 \mathrm{ppm}$ and $10 \mathrm{ppm}$ of ethylene, propene and allene respectively. $T=296 \mathrm{~K} ; \mathrm{P}=760$ Torr.

Additionally, to demonstrate the potential of this sensor to measure trace species in the atmosphere, ethylene concentrations were measured in air samples collected from our laboratory and from an automobile parking garage. Due to the potential interference from carbon dioxide at $949.47 \mathrm{~cm}^{-1}$, these ethylene measurements were carried out at a nearby frequency of $949.835 \mathrm{~cm}^{-1}$. The sample collected from the automobile garage had significantly larger concentration of ethylene ( $415 \mathrm{ppb}$ ) compared to the sample collected from laboratory air (55 ppb). The elevated levels of ethylene in the garage air sample are attributed to the unburnt hydrocarbon exhaust from automobiles and lie within the previously reported values of 17 to $800 \mathrm{ppb}$ measured in urban areas [43].

The pulsed CRDS diagnostic developed in this study is able to achieve sub-ppm detection limits for ethylene, propene, allene and 1-butene. Further improvements in absorption sensitivity are possible by utilizing higher reflectivity mirrors in conjunction with higher power lasers [30]. A laser source that does not suffer from mode-hops will also improve the overall operation of the sensor. 


\section{Conclusions}

A novel widely-tunable sensor based on pulsed cavity ringdown spectroscopy has been successfully developed and used for performing sensitive absorption measurements of ethylene, propene, allene and 1butene in the mid-IR. The high sensitivity of the laser-based sensor enabled detection limits of $17 \mathrm{ppb}, 134$ ppb, $754 \mathrm{ppb}$ and $378 \mathrm{ppb}$ for ethylene, propene, allene and 1-butene, respectively at a nominal temperature of $296 \mathrm{~K}$ and pressure of 760 Torr. Trace amounts of ethylene, propene, allene and 1-butene were measured individually as well as simultaneously in a multi-gas mixture containing gases at $1 \%$ of their TWA exposure limits. To the best of our knowledge, this work represents one of the first suecessful implementations of the pulsed CRDS technique to measure trace amounts of multiple gases in the mid-IR $\left(900-1000 \mathrm{~cm}^{-1}\right)$ region. Furthermore, this is the first laser-based sensor capable of measuring trace amounts of propene, allene, and 1-butene.

Acknowledgements. Research reported in this publication was funded by King Abdullah University of Science and Technology (KAUST) under the competitive center funding (CCF) program.

\section{References}

[1] Narasimhan L R, Goodman W and Patel C K 2001 Correlation of breath ammonia with blood urea nitrogen and creatinine during hemodialysis. Proc. Natl. Acad. Sci. U. S. A. 98 4617-21

[2] Lewicki R, Kosterev A A, Thomazy D M, Risby T H, Solga S, Schwartz T B and Tittel F K 2011 Real time ammonia detection in exhaled human breath using a distributed feedback quantum cascade laser based sensor Proc. SPIE 794579450K-79450K-7

[3] Owen K and Farooq A 2014 A calibration-free ammonia breath sensor using a quantum cascade laser with WMS 2f/1f Appl. Phys. B Lasers Opt. 116 371-83

[4] Cao Y, Sanchez N P, Jiang W, Griffin R J, Xie F, Hughes L C, Zah C and Tittel F K 2015 Simultaneous atmospheric nitrous oxide, methane and water vapor detection with a single continuous wave quantum cascade laser Opt. Express 232121

[5] Weidmann D, Kosterev A A, Roller C, Curl R F, Fraser M P and Tittel F K 2004 Monitoring of ethylene by a pulsed quantum cascade laser Appl. Opt. 43 3329-34

[6] Sun K, Sur R, Chao X, Jeffries J B, Hanson R K, Pummill R J and Whitty K J 2013 TDL absorption sensors for gas temperature and concentrations in a high-pressure entrained-flow coal gasifier Proc. Combust. Inst. 34 3593-601

[7] Schroeder P J, Wright R J, Coburn S, Sodergren B, Cossel K C, Droste S, Truong G W, Baumann E, Giorgetta F R, Coddington I, Newbury N R and Rieker G B 2017 Dual frequency comb laser absorption spectroscopy in a $16 \mathrm{MW}$ gas turbine exhaust Proc. Combust. Inst. 36 4565-73 
[8] Pushkarsky M B, Dunayevskiy I G, Prasanna M, Tsekoun A G, Go R and Patel C K N 2006 Highsensitivity detection of TNT. Proc. Natl. Acad. Sci. U. S. A. 103 19630-4

[9] Harb C C, Boyson T K, Kallapur a G, Petersen I R, Calzada M E, Spence T G, Kirkbride K P and Moore D S 2012 Pulsed quantum cascade laser-based CRDS substance detection: real-time detection of TNT. Opt. Express 20 15489-502

[10] Curran H J, Gaffuri P, Pitz W J and Westbrook C K 1998 A comprehensive modeling study of n-heptane oxidation Combust. Flame 114 149-77

[11] Westbrook C K, Pitz W J, Herbinet O, Curran H J and Silke E J 2009 A comprehensive detailed chemical kinetic reaction mechanism for combustion of $n$-alkane hydrocarbons from $n$-octane to $n$-hexadecane Combust. Flame 156 181-99

[12] Yang B, Wang J, Cool T A, Hansen N, Skeen S and Osborn D L 2012 Absolute photoionization crosssections of some combustion intermediates Int. J. Mass Spectrom. 309 118-28

[13] Chakir A, Cathonnet M, Boettner J C and Gaillard F 1989 Kinetic study of 1-butene oxidation in a jetstirred flow reactor Symp. Combust. 22 873-81

[14] Kosterev A, Wysocki G, Bakhirkin Y, So S, Lewicki R, Fraser M, Tittel F and Curl R F 2008 Application of quantum cascade lasers to trace gas analysis Appl. Phys. B 90 165-76

[15] Chrystie R S M, Nasir E F and Farooq A 2015 Propene concentration sensing for combustion gases using quantum-cascade laser absorption near $11 \mu \mathrm{m}$ Appl. Phys. B Lasers Opt. 120 317-27

[16] Rich S 1964 Ozone damage to plants Annu. Rev. Phytopathol. 2 253-66

[17] Wilkinson S, Mills G, Illidge R and Davies W J 2012 How is ozone pollution reducing our food supply? J. Exp. Bot. 63 527-36

[18] Amann M and Lutz M 2000 The revision of the air quality legislation in the European Union related to ground-level ozone J. Hazard. Mater. 78 41-62

[19] van Zelm R, Huijbregts M A J, den Hollander H A, Van Jaarsveld H A, Sauter F J, Struijs J, van Wijnen H J and van de Meent D 2008 European characterization factors for human health damage of PM 10 and ozone in life cycle impact assessment Atmos. Environ. 42 441-53

[20] Altuzar V, Pacheco M, Tomás S A, Arriaga J L, Zelaya-Angel O and Sánchez-Sinencio F 2001 Analysis of ethylene concentration in the Mexico City atmosphere by photoacoustic spectroscopy Anal. Sci 17 541-54

[21] Wahl E, Tan S, Koulikov S, Kharlamov B, Rella C, Crosson E, Biswell D and Paldus B 2006 Ultrasensitive ethylene post-harvest monitor based on cavity ring-down spectroscopy Opt. Express 14 1673-84

[22] Manne J, Jäger W and Tulip J 2008 Pulsed quantum cascade laser based cavity ring-down and cavity enhanced spectroscopy for the detection of ethylene. Photonics North 2008 (International Society for Optics and Photonics) p 709922

[23] Manne J, Jäger W and Tulip J 2009 Sensitive detection of ammonia and ethylene with a pulsed quantum cascade laser using intra and interpulse spectroscopic techniques Appl. Phys. B 94 337-44 
[24] He X, Walton S M, Zigler B T, Wooldridge M S and Atreya A 2007 Experimental investigation of the intermediates of isooctane during ignition Int. J. Chem. Kinet. 39 498-517

[25] OKeefe A and Deacon D A G 1988 Cavity ring-down optical spectrometer for absorption measurements using pulsed laser sources Rev. Sci. Instrum. $592544-51$

[26] Scherer J J, Paul J B, O’keefe A and Saykally R J 1997 Cavity ringdown laser absorption spectroscopy: history, development, and application to pulsed molecular beams Chem. Rev. 97 25-52

[27] Berden G, Peeters R and Meijer G 2000 Cavity ring-down spectroscopy: Experimental schemes and applications Int. Rev. Phys. Chem. 19 565-607

[28] Manne J, Sukhorukov O, Jäger W and Tulip J 2006 Pulsed quantum cascade laser-based cavity ring-down spectroscopy for ammonia detection in breath Appl. Opt. 45 9230-7

[29] Rao G N and Karpf A 2010 High sensitivity detection of $\mathrm{NO}_{2}$ employing cavity ringdown spectroscopy and an external cavity continuously tunable quantum cascade laser Appl. Opt. 49 4906-14

[30] Alquaity A B S, Es-sebbar E and Farooq A 2015 Sensitive and ultra-fast species detection using pulsed cavity ringdown spectroscopy Opt. Express $\mathbf{2 3} 7217$

[31] Xu S, Sha G and Xie J 2002 Cavity ring-down spectroscopy in the liquid phase Rev. Sci. Instrum. 73 255-8

[32] Snyder K L and Zare R N 2003 Cavity ring-down spectroscopy as a detector for liquid chromatography Anal. Chem. 75 3086-91

[33] Rothman L S, Gordon I E, Barbe A, Benner D C, Bernath P F, Birk M, Boudon V, Brown L R, Campargue A, Champion J-P, Chance K, Coudert L H, Dana V, Devi V M, Fally S, Flaud J-M, Gamache R R, Goldman A, Jacquemart D, Kleiner I, Lacome N, Lafferty W J, Mandin J-Y, Massie S T, Mikhailenko S N, Miller C E, Moazzen-Ahmadi N, Naumenko O V, Nikitin A V, Orphal J, Perevalov V I, Perrin A, Predoi-Cross A, Rinsland C P, Rotger M, Šimečková M, Smith M A H, Sung K, Tashkun S A, Tennyson J, Toth R A, Vandaele A C and Vander Auwera J 2009 The HITRAN 2008 molecular spectroscopic database J. Quant. Spectrosc. Radiat. Transf. $110533-72$

[34] Huang H and Lehmann K K 2010 Long-term stability in continuous wave cavity ringdown spectroscopy experiments Appl. Opt. 491378

[35] Sharpe S W, Johnson T J, Sams R L, Chu P M, Rhoderick G C and Johnson P A 2004 Gas-phase databases for quantitative infrared spectroscopy Appl. Spectrosc. 58 1452-61

[36] Es-sebbar E touhami, Alrefae M and Farooq A 2014 Infrared cross-sections and integrated band intensities of propylene: Temperature-dependent studies J. Quant. Spectrosc. Radiat. Transf. 133 559-69

[37] Es-Sebbar E T, Benilan Y and Farooq A 2013 Temperature-dependent absorption cross-section measurements of 1-butene (1-C4H8) in VUV and IR J. Quant. Spectrosc. Radiat. Transf. 115 1-12

[38] Es-Sebbar E, Jolly A, Benilan Y and Farooq A 2014 Quantitative mid-infrared spectra of allene and propyne from room to high temperatures J. Mol. Spectrosc. 305 10-6

[39] Ren W, Davidson D F and Hanson R K 2012 IR laser absorption diagnostic for C2H4 in shock tube kinetics 
1

2

3

4

5

6

7

8

9

10

11

12

13

14

15

16

17

18

19

20

21

22

23

24

25

26

27

28

29

30

31

32

33

34

35

36

37

38

39

40

41

42

43

44

45

46

47

48

49

50

51

52

53

54

55

56

57

58

59

60

studies Int. J. Chem. Kinet. 44 423-32

[40] Alrefae M, Es-sebbar E and Farooq A 2014 Absorption cross-section measurements of methane, ethane, ethylene and methanol at high temperatures J. Mol. Spectrosc. 303 8-14

[41] Airgas Inc. 2015 Material Safety Data Sheet Flammable Gas Mixture: 1-Butene / Cis-2-Butene / Ethane / Ethylene / Isobutane / Isobutylene (Isobutene) / Isopentane / Methane / N-Butane / N-Pentane / Propane / Propylene / Trans-2-Butene

[42] Airgas Inc. 2009 Material Safety Data Sheet Flammable Gas Mixture: 1,2-Propadiene 0.1-10\% / Methane $90-99 \%$

[43] Aikin A C, Herman J R, Maier E J and McQuillan C J 1982 Atmospheric chemistry of ethane and ethylene J. Geophys. Res. Ocean. 87 3105-18 